Published in final edited form as:

Pain. 2013 August ; 154(8): 1295-1304. doi:10.1016/j.pain.2013.04.004.

\title{
Temporomandibular joint pain: A critical role for Trpv4 in the trigeminal ganglion
}

\author{
Yong Chen ${ }^{a}$, Susan H. Williams ${ }^{b, \#}$, Amy L. McNulty ${ }^{c, \#}$, Ji Hee Honga,d, Suk Hee Lee ${ }^{a}$, Nicole \\ E. Rothfusz ${ }^{\mathrm{c}}$, Puja K. Parekh ${ }^{\mathrm{a}}$, Carlene Moore ${ }^{\mathrm{a}}$, Robert Gereau IV ${ }^{\mathrm{h}}$, Andrea B. Taylore,f, Fan \\ Wang $^{\mathrm{g}}$, Farshid Guilak ${ }^{\mathrm{c}}$, and Wolfgang Liedtke ${ }^{\mathrm{a}, \mathrm{d}, \mathrm{i},{ }^{*}}$ \\ aDuke University Dept. of Medicine, Durham, NC \\ 'Duke University Dept. of Orthopaedic Surgery, Durham, NC \\ eDuke University Dept. of Community and Family Medicine, Durham, NC \\ fDuke University Dept. of Evolutionary Anthropology, Durham, NC \\ gDuke University Dept. of Cell Biology, Durham, NC \\ bOhio University, Heritage College of Osteopathic Medicine, Athens, $\mathrm{OH}$ \\ dDuke Clinics for Pain and Palliative Care, Durham, NC \\ iDuke Center for Neuroengineering, Durham, NC \\ hWashington University, Dept. of Anesthesiology, St. Louis MO
}

\section{Abstract}

\begin{abstract}
Temporomandibular joint disorder (TMJD) is known for its mastication-associated pain. TMJD is medically relevant because of its prevalence, severity, chronicity, and "therapy-refractoriness" of its pain, and its largely elusive pathogenesis. Against this background we sought to investigate pathogenetic contributions of the calcium-permeable TRPV4 ion channel, robustly expressed in the trigeminal ganglion sensory neurons, to TMJ inflammation and pain behavior. We demonstrate here that TRPV4 is critical for TMJ-inflammation evoked pain behavior in mice, and that trigeminal ganglion pro-nociceptive changes are Trpv4dependent. As a quantitative metric, bite force was recorded as evidence of masticatory sensitization, in keeping with human translational

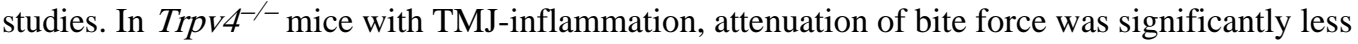
than in WT mice. Similar effects were seen with systemic application of a specific TRPV4 inhibitor. TMJ-inflammation and mandibular bony changes were apparent after CFA injections,
\end{abstract}

(C) 2013 International Association for the Study of Pain. Published by Elsevier B.V. All rights reserved

* corresponding author: Dr. Wolfgang Liedtke, Duke University Medical Center, Department of Medicine/Division of Neurology; Duke Clinics for Pain and Palliative Care, Durham NC 27710 USA, wolfgang@ neuro.duke.edu; Tel.: +1-919-6840058; Fax: +1-919-6846514

\# equal contribution

Contributions:

Experimentation: YC, ALM, JHH, SHL, NER, PKP, CM

Critical Resources: SW, ABT, FG

Data analysis: SW, YC, ALM, NER

Concept and idea: YC, SW, RG, ABT, FW, FG, WL

Paper writing: YC, ALM, NER, RG, ABT, FW, FG, WL

No conflict of interest on behalf of the authors.

Publisher's Disclaimer: This is a PDF file of an unedited manuscript that has been accepted for publication. As a service to our customers we are providing this early version of the manuscript. The manuscript will undergo copyediting, typesetting, and review of the resulting proof before it is published in its final citable form. Please note that during the production process errors may be discovered which could affect the content, and all legal disclaimers that apply to the journal pertain. 
but remarkably independent of Trpv4 genotype. Intriguingly, as a result of TMJ-inflammation, WT mice exhibited significant up-regulation of TRPV4 and phosphorylated ERK in TMJinnervating trigeminal sensory neurons, absent in $\operatorname{Trp} v 4^{-1}$ mice. Mice with genetically-impaired MEK/ERK phosphorylation in neurons showed a similar resistance to reduction of bite-force as Trpv4 ${ }^{-/}$mice. Thus, TRPV4 is necessary for masticatory sensitization in TMJ-inflammation, and likely functions up-stream of MEK/ERK phosphorylation in trigeminal ganglion sensory neurons in-vivo. TRPV4 therefore represents a novel pro-nociceptive target in TMJ inflammation, and should be considered a target-of-interest in human TMJD.

\section{Introduction}

Mastication is of fundamental relevance for all vertebrates. It is a highly sophisticated behavior, which, in terms of neural control, is dominated by the motor and sensory components of the trigeminal system and their central projections $[12 ; 21 ; 30 ; 45 ; 48]$. Neural control of mastication, which can involve the generation of very high bite forces over milliseconds, also comprises ultra-rapid sensory feedback from innervated cranio-facial structures that are involved in chewing, namely jawbones, their unique joint with the skull, the temporomandibular joint (TMJ), masticatory muscles and teeth $[21 ; 30 ; 36 ; 45 ; 48]$. Under most normal circumstances, mastication as a component of instinctive behavior is not consciously perceived by humans. However, in cases of tissue injury to relevant structures, mastication can become painful leading to reduced bite force $[2 ; 23 ; 43]$. This can be understood as a specific case of mechanical allodynia - "masticatory" allodynia, which eventually leads to reduced food intake $[16 ; 18 ; 34]$. In this regard, temporomandibular joint disorder (TMJD) is particularly relevant $[12 ; 30 ; 31 ; 44]$. It is a treatment-refractory trigeminal pain disorders that is challenging to patients and their caregivers $[3 ; 37]$. One of the obstacles towards development of rationally-targeted therapies is shortcomings of available animal models for TMJD, especially the relative paucity of objective measurements that accurately represent patients' cardinal complaints. Another roadblock is lack of clear understanding of molecular, cellular and neural-circuit mechanisms that underlie TMJ pain and dysfunction.

In this study, we investigated the mechanisms of nociception evoked by TMJ inflammation by using mice genetically engineered to lack $\operatorname{Tr} p V 4[28 ; 29 ; 32 ; 42]$. TRPV4 ion channels can be multimodally activated to permeate cations, with a moderate preference for $\mathrm{Ca}^{++}$ over $\mathrm{Na}^{+}$. Amongst other cues, responses to mechanical stimuli were found to involve TRPV4. Its expression has been demonstrated in trigeminal ganglion (TG) neurons at more robust levels than in DRG, and TRPV4 has been implicated in nociception both physiologically and in sensitized states such as nerve injury and inflammation, in particular for mechanically-evoked pain $[1 ; 7 ; 26 ; 28 ; 29 ; 48]$. We therefore subjected $\operatorname{Trp} 4^{-/}$and WT mice to bilateral TMJ inflammation and measured bite force, a significant extension of current practice for assessment of nocifensive behavior in TMJ inflammation [47]. Our results suggest that TRPV4 is a critical pro-nociceptive signaling molecule in the pathogenesis of TMJ-associated pain, and that its TG expression could be highly relevant for pain behavior and nociceptive signaling.

\section{Materials and methods}

\subsection{Animals}

The pan-null phenotype of Trpv4-/- mice [29] relies on excision of the exon encoding transmembrane domains 5-6. Mice were outcrossed to C57BL/6J background and PCRgenotyped. Male WT and Trpv $4^{-/}$mice, 3-4 months of age, were used for all experiments, and bite force was also recorded in female mice of the same age. 
Male dominant-negative MEK transgenic mice [41], 3-4 months of age, were used. The neuron-specific and pan-neuronal Ta $1 \mathrm{a}$-tubulin promoter was used to drive the transgene. We documented expression of dnMEK in sensory neurons of the trigeminal ganglion (Fig. $6 \mathrm{C})$.

Animals were housed in climate-controlled rooms on a 12/12h light/dark cycle with water and standardized rodent diet available ad libitum. All animal protocols were approved by the Duke University IACUC in compliance with NIH guidelines.

\subsection{Induction of TMJ inflammation, neural tracing, and chemical injections}

All mice were briefly anesthetized with $2 \%$ isoflurane and bilaterally injected using a $30 \mathrm{G}$ needle on a $10 \mu \mathrm{L}$ Hamilton syringe. To induce chronic inflammation of the TMJ, $10 \mu \mathrm{L}$ of complete Freund's adjuvant (CFA, $5 \mathrm{mg} / \mathrm{mL}$; Chondrex) were injected, targeting both TMJs. Since the bite performed by the mice was an incisor bite, also to reduce variability of reduction of bite force, both TMJs were injected. Control animals were injected with the same volume of incomplete Freund's adjuvant (IFA, Chondrex). To track TMJ innervation, mice were injected with $1.5 \mu \mathrm{L}$ of neural tracer Fast-Blue (FB, 2\% aqueous solution, Polysciences) into TMJ 15 min before CFA or IFA administration.

Moistened food pellets were made available to animals after induction of TMJ inflammation to decrease food consistency. To investigate the effects of the non-steroidal antiinflammatory drug Ketorolac and the specific TRPV4 inhibitor HC-067047 on CFA-induced attenuation of bite force, mice received a single intraperitoneal administration of Ketorolac $(7.5 \mathrm{mg} / \mathrm{kg}$, dissolved in normal saline; Sigma) or HC-067047 (10 mg/kg, dissolved in $6 \%$ DMSO; Sigma) on day 1 after CFA injection, and were measured for bite force changes at $1 \mathrm{~h}, 3 \mathrm{~h}$ and $5 \mathrm{~h}$ following treatment. Control animals received the same volume of NS or $6 \%$ DMSO. For testing the effect of the compounds on bite force in the absence of induced TMJ inflammation, mice received the same dose of Ketorolac or HC-067047, without concomitant TMJ injection.

\subsection{Bite force and bite rate analysis}

Mice were acclimated to testing facility and handling for 2 days prior to behavioral testing.

Bite force was measured using a custom-made bite force transducer designed as described previously [47]. Briefly, the transducer consists of two aluminum beams, each instrumented with two single-element strain gauges (TML UFLA-1-350-11-3LT). The four strain gauges are connected in a Wheatstone bridge. Deformation of parallel-mounted beams results in a proportional change in resistance and subsequently in the voltage output to the Wheatstone bridge. One end of each beam served as bite plate and was covered with an acrylic coating (Micro-Measurements) to protect the animals' teeth. Prior to each use, the bite force transducer was calibrated and checked for linearity by suspending a series of calibration weights ranging from 0.1 to $0.5 \mathrm{~kg}$ from the bite plates. The voltage output from each weight was regressed against force exerted by calibration weights. Output for each set of calibrations was both linear and reproducible, with correlation coefficients $\left(\mathrm{R}^{2}\right)$ ranging from $0.9901-0.9997$ for each calibration. The distance between the beams of the bite force transducer was adjusted to $4.5 \mathrm{~mm}$ ( $40 \%$ of maximal jaw gape) at which mice can produce the maximum bite forces [47]. Mice were placed in a cylindrical tube with an opening at one end for accommodation of the mouse's head. When the bite transducer was moved towards the mouse at $0.5-1 \mathrm{~cm} / \mathrm{sec}$, a bite was invariably elicited. The voltage output during each bite was recorded as a continuous wave at $500 \mathrm{~Hz}$ using Labview8.0 (National Instruments). The peak voltage of each bite was determined and converted into force $(\mathrm{N})$ based on the regression equation derived from calibration. Each animal was tested 5x/testing day. The 
interval between two trials was $>1$ min. The highest force the animal generated per trial was recorded as bite force, then averaged for all trials.

Bite rate analyses were performed as previously described [39]. The biting rate was calculated as peak bite force magnitude divided by duration of biting. Two biting rates, i.e. loading (5\% of peak force to peak; rate 1) and unloading (peak to $5 \%$ of peak force, rate 2), were determined.

\subsection{Jaw morphometry}

Considering bite force can be influenced by jaw-muscle anatomy [47], maximum gapes were determined immediately post-mortem by opening the jaws with a forceps. Care was taken not to avulse any of the soft and hard tissues of the TMJ. Using a digital caliper, we measured the maximum linear distance between the upper and lower incisor tips to the nearest $0.1 \mathrm{~mm}$. After dissection, in addition, jaw length was determined as the maximum linear distance from the caudal surface of the mandibular condyle to the tip of the lower incisor.

\subsection{Immunohistohemistry and morphometry}

Routine procedures were followed [29]. Briefly, mice were perfused transcardially with $0.01 \mathrm{M}$ PBS followed by ice-cold 4\% PFA at the experimental time-point under study. Their TGs were dissected and post-fixed in 4\% PFA overnight, cryoprotected in $20 \%$ sucrose (48h) and sectioned on a cryostat at $12 \mu \mathrm{m}$. Brainstem sections were processed similarly and sectioned at $30 \mu \mathrm{m}$. Sections were blocked with 5\% normal goat serum (Jackson), and incubated overnight with primary antibodies: rabbit anti-TRPV4 (1:300, Abcam), mouse anti-NF200 (1:10000, Sigma), mouse anti-peripherin (1:200, Millipore), guinea pig antiCGRP (1:2000, Bachem), anti-IB4 ( $2 \mu \mathrm{g} / \mathrm{mL}$, biotinylated, Vector-Labs), rabbit anti-HA (1:500, Santa Cruz), rabbit anti-pERK (1:250, Cell Signaling Technology), mouse antipERK (1:600, Cell Signaling Technology; for double-labeling with TRPV4 in TG), and mouse anti-Brn-3a (1:200, Millipore; for brainstem sections only). Immunodetection was accomplished with secondary antibodies (AlexaFluor594-conjugated goat anti-rabbit; AlexaFluor488-conjugated goat anti-mouse or -guinea pig; all 1:500; Invitrogen) for $2 \mathrm{~h}$, and cover-slipped with Vectashield (Vector). Digital micrographs were acquired using a BX61 Olympus upright microscope equipped with high-resolution CCD camera and with constant acquisition/exposure settings, using ISEE software (ISEE Imaging Systems, Raleigh NC). TGs from $\operatorname{Trpv}^{-/-}$mice were also stained to validate specificity of TRPV4 immunolabeling.

For every animal under study, 4-6 TG sections were analyzed per mouse; neurons were identified by morphology. The cutoff density threshold was determined by averaging the density of three neurons per section that were judged to be minimally positive, using Image J software. All neurons for which the mean density exceeded the threshold $>25 \%$ were counted as positive, and the positive cells were expressed as a percentage of total counted TG neurons.

\subsection{Trpv4-copGFP transgenic mice}

Generation and characterization of this mouse line have been reported previously [40]. Briefly, in a BAC transgene, the murine full-length Trpv4 promoter drives copepod-GFP. Deletion of exons 10-14 assures that a functional ion channel cannot arise. TMJ inflammation was induced in male transgenic mice, 3-4 months of age, and TGs were dissected on d3 post-injection. Native GFP-fluorescence was assessed in $12 \mu \mathrm{m}$ fresh-frozen sections, unfixed and embedded using fluoromount, imaged with constant acquisition/ exposure parameters, from both CFA and IFA-injected mice. $225 \mathrm{TG}$ neurons per animal 
were assessed by densitometry (ImageJ). For this, only neurons above a cutoff density ( $3 \mathrm{x}$ the density of the minimally fluorescent neurons in the respective animal) were evaluated. Customized regions-of-interest that did not include the nucleus were used. Mean densities were background-subtracted, and the average value per animal (from all neurons assessed) was determined to yield the group average.

\subsection{Western blot}

Routine procedures were followed [29]. Briefly, snap-frozen TGs were protein-extracted in CHAPS, and electroblotted to nitrocellulose membranes after gel separation of proteins in a $10 \%$ polyacrylamide gel. Membranes were blocked with 5\% dry-milk, TRPV4 was specifically detected with primary antibody (rabbit anti-TRPV4, 1:1000; Alomone), secondary antibody (anti-rabbit peroxidase-conjugated, 1:5000; Jackson ImmunoResearch) and chemoluminescence substrate (ECL-Advance, GE Healthcare). Abundance was quantified using ImagePro Plus software. Specificity of the antibody was confirmed using $T r p v 4^{-/-}$TG. Neuronal isoform of $\beta$-tubulin was detected with a mouse monoclonal anti- $\beta$ tub $_{\text {III }}$ antibody (1:5000, Iowa Hybridoma Bank).

\subsection{Quantitative real-time PCR}

Total RNA was isolated from mouse TG using TRIzol reagent (Invitrogen). After purification, $5 \mu \mathrm{g}$ of total RNA were DNase I-treated using RNase-free DNase (Qiagen) followed by RNeasy Cleanup (Qiagen). $1 \mu \mathrm{g}$ of total RNA was then reverse transcribed using oligo primers (dT) and SuperScriptIII first-strand synthesis kit (Invitrogen). Gene expression was assessed by quantitative real-time PCR using $2 \times$ SYBR Green Master Mix (Applied Biosystems) and a two-step cycling protocol (anneal/elongate at $60^{\circ} \mathrm{C}$, denature at $95^{\circ} \mathrm{C}$ ). Specificity of primers was verified by dissociation/melting curve for the amplicons when using SYBR Green as a detector. All reactions were performed in triplicate. The amount of target messenger RNA (mRNA) in the experimental group relative to that in the control was determined from the resulting fluorescence and threshold values $(\mathrm{Ct})$ using the $\Delta \Delta \mathrm{Ct}$ method. Primer sequences for "pain-TRPs" are shown in table below. $\beta_{\mathrm{III}}$-tubulin was used as housekeeping gene.

\begin{tabular}{|c|c|}
\hline Primer & Primer sequence \\
\hline \multirow{2}{*}{ Trpv1 } & Forward: 5'-GCCCTGGTTCCCCTTCTG-3' \\
\hline & Reverse: 5'-TTCCGGCTGGGTGCTATG-3' \\
\hline \multirow{2}{*}{ Trpv2 } & Forward: $5^{\prime}$-TGATGAAGGCTGTGCTGAAC-3' \\
\hline & Reverse: $5^{\prime}$-CACCACAGGCTCСТCTTCTC-3' \\
\hline \multirow{2}{*}{ Trpv3 } & Forward: 5'-CCAAGACCTCTCCACCCATCT-3' \\
\hline & Reverse: 5'-AGGCACTGCCGGATGTTG-3' \\
\hline \multirow{2}{*}{ Trpa1 } & Forward: 5'-TCCATGGGTGGGTACACTCA-3' \\
\hline & Reverse: 5'-TCGGTCTGTGCATTTCAAGTTAG-3' \\
\hline \multirow{2}{*}{ Trpm2 } & Forward: $5^{\prime}$-TGGCTTCTAAGAGGAAAGTACA-3' \\
\hline & Reverse: 5'-AGTCCTGAAGTTTTCCAAGATT-3' \\
\hline \multirow{2}{*}{ Trpm3 } & Forward: $5^{\prime}$-GGCAATCAAATATAGTCAAGGA-3' \\
\hline & Reverse: 5'-ATGTTAGATCTTCCCACCTTTT-3' \\
\hline \multirow{2}{*}{ Trpm8 } & Forward: 5'-CCCTCCTCCAGTGAGCTAAGAG-3' \\
\hline & Reverse: 5'-GCTCAATCAGCCAAGAGCTTCT-3' \\
\hline$\beta_{\mathrm{III}}$-tubulin & Forward: 5'-GCCATGTTCCGGCGCAAGGCCTTC-3' \\
\hline
\end{tabular}




\begin{tabular}{ll}
\hline Primer & Primer sequence \\
\hline & Reverse: $5^{\prime}$-GCAGTGGCGTCCTGGTACTGCTGG-3' \\
\hline
\end{tabular}

\subsection{Micro-CT scanning and histopathological analyses of TMJ}

TMJ with soft connective tissues was carefully dissected and post-fixed in 4\% PFA for 48h, and then placed in $70 \%$ Ethanol at $4{ }^{\circ} \mathrm{C}$ until used. For quantitative 3-D evaluation of the mandibular condyle, the right TMJ was scanned by a micro-CT system (micro-CT 40, Scanco Medical AG). Samples were scanned at $55 \mathrm{kV}$ with a slice increment of $16 \mu \mathrm{m}$. Calcified tissues were segmented from soft tissues using a threshold of 360 . The head of the mandibular condyle was defined as the "cap-shaped" region at the end of the condyle and included approximately 90 slices. A 3-D reconstruction was generated of this region and analyzed using the internal software of the micro-CT system to determine bone volume $\left(\mathrm{mm}^{3}\right)$, total volume $\left(\mathrm{mm}^{3}\right)$ and calcified bone fraction (bone volume/total volume) for both WT and Trpv $4^{-/}$naïve, day 13 IFA injected, and day 13 CFA injected mice.

To evaluate synovial inflammation, histological sections were prepared of the TMJs from samples that were scanned on the micro-CT. The joint samples were decalcified for 6 days at $4^{\circ} \mathrm{C}$ in Cal-Ex (Fisher-Scientific). Next, the TMJs were dehydrated and paraffin embedded in a Leica ASP300 tissue processor (Leica Microsystems Inc) followed by vacuum infiltration with paraffin for generation of $8 \mu \mathrm{m}$ sections throughout the entire joint (sagittal plane). Sections from the central region of the joint were stained with Harris Hematoxylin and Eosin Phloxine (Poly Scientific) and then graded using a modified Gynther grading system [17], including synovial hyperplasia (0 to 4 ) for each synovial lining layer in the TMJ (for a maximum score of 16 for total synovial hyperplasia) and vascularity (0-4). Total hyperplasia was reported as the sum of the histological grading score for all four synovial membranes per TMJ. The synovitis score was determined as the sum of the total hyperplasia score and vascularity score for each TMJ. For all parameters, 0 is normal and the higher the score, the more severe the joint changes. Scores were determined by averaging the values from three blinded graders.

\subsection{Statistical analysis}

All data are expressed as mean \pm SEM. Two-tail t-tests or one-way ANOVA followed by Tukey post-hoc test were used for group comparison. The histological scores of TMJ were not normally distributed, thus the non-parametric Kruskall-Wallis test was performed to determine significant differences. $\mathrm{P}<0.05$ indicated statistically significant differences.

\section{Results}

\subsection{TMJ inflammation attenuates bite force in mice}

We were able to accurately determine bite force in mice, using a custom-built force transducer fitted to their gape (Fig. 1A-B, Suppl. Fig. 1) [39; 47]. Mice bit with forces of $14-15 \mathrm{~N}$. The evoked bite appeared aggressive in nature, in response to the slowly approaching transducer. We believe the provoked aggression that prompted the bite to be a valid method to assess bite force because recorded responses were immediate, robust and reproducible.

TMJ-inflammation was elicited by microinjecting complete Freund's adjuvant (CFA) (Fig. 1A-B), and control injections were with incomplete Freund's adjuvant (IFA). With this protocol, we could observe a prolonged and significant attenuation of bite force over 9 days (Fig. 1B). Bite force returned to $>80 \%$ of baseline within 2 weeks. To assess bite force 
dynamics, we determined bite rates, defined as increase/decrease in force over time, leading to loading and unloading rate (Suppl. Fig. 2) [8; 39]. Bite rate time-courses paralleled the time-course of maximum force because bite duration was not significantly changed (Suppl. Fig. 2). Body weight was reduced $₫ 0 \%$ (not shown). The reduction of bite force in the absence of a robust reduction in body weight suggests induction of masticatory sensitization rather than general inflammatory and anorexic effects of inflammation. Pain behavior in our TMJ-inflammatory model was responsive to systemic application of the non-steroidal-antiinflammatory, ketorolac, confirming the validity of the model (Fig. 1C). Next, we assessed skeletal changes of TMJ-inflammation by micro-CT of the mandibular condyle and TMJ histology $[9 ; 14]$. The bone matrix was severely affected by TMJ-inflammation, evidenced by significant reduction of calcified bone fraction (from $0.83 \pm 0.01$ to $0.58 \pm 0.04$ for $13 \mathrm{~d}$ IFA vs. 13d CFA; Fig. 1D). Joint histology showed increased synovial hyperplasia- (from $1.83 \pm 0.75$ to $4 \pm 1.97$ ) and synovitis (from $2.83 \pm 1.10$ to $5.06 \pm 2.29$ ) indices on d13 for IFA vs. CFA injections (Fig. 1E). These radiologic and histopathologic findings provide further evidence of the direct targeting of the TMJ with CFA injections, rather than surrounding masticatory muscles, because a CFA-induced myositis of masticatory muscles would not induce TMJ arthritic changes and mandibular condyle bone loss to the degree we have observed.

\subsection{Trpv4 is necessary for attenuation of bite force in response to TMJ inflammation}

We took advantage of this methodology to study the role of Trpv4 in TMJ inflammatory pain by comparing $\operatorname{Trpv4^{-/}}$ pan-null mice [29] with their WT controls. The rationale for this is based on (1) the extraordinary level of mechanical "masticatory" allodynia present in TMJD; (2) the evidence for TRPV4's involvement in mechanical signal transduction; (3) the record of TRPV4 in inflammatory pain conditions. First, we confirmed that TRPV4 is expressed in the TG (34.3\% of total TG neurons), using specific antibody, revealing an expression pattern similar to that reported previously [28; 29; 46] (Fig. 2A-B and Fig 4B). We also conducted co-labeling experiments that revealed TRPV4-expressing TG neurons to be $27.3 \%$ peptidergic, $11.2 \%$ non-peptidergic, to express NF200 (marker of TG neurons with myelinated axons) in $67.2 \%$ and peripherin (marker of small-size TG neurons) in $22.1 \%$ (Fig. 2C). We then performed neural tracing with Fast-Blue (FB) injected into the TMJ (Fig. 2A). This resulted in labeling of $6.5 \%$ of all TG neurons, and $\approx 50 \%$ of those expressing TRPV4 (=3\% TRPV4+/FB+). Thus, the TMJ is innervated by TRPV4expressing TG sensory neurons. When we re-assessed the lineages in TRPV4+/FB+ TG neurons, we found 50.4\% to express CGRP (peptidergic), 36.7\% to express IB4 (nonpeptidergic), $47.0 \%$ to express peripherin, and 56.0\% to express NF200 (Fig. 2C). These data suggest that the TMJ is innervated robustly by TRPV4-expressing TG neurons, and that a substantial number of TRPV4-expressing, TMJ-innervating TG neurons might function as nociceptors. We also studied TRPV4 expression in sensory neurons of the proprioceptive mesencephalic trigeminal nucleus. We were unable to identify TRPV4-expressing neurons here (Suppl. Fig. 3).

Overall, these TMJ tracing- and TRPV4 expression studies provide a sound rationale for comparing $\operatorname{Trpv4^{-/}}$ mice with WT controls in our inflammatory TMJD model. This approach will inform us whether Trpv4 contributes towards bite physiology as well as masticatory sensitization. Whereas, in the non-inflamed state, we were unable to identify differences between genotypes in TMJ anatomy (Suppl. Fig. 4), nor at the functional level for bite force and bite rates, striking differences became apparent in response to TMJ inflammation. This could be observed at similar levels and time-dynamics for both sexes (Fig. 3A). Attenuation of bite force was conspicuously reduced in $\operatorname{Trpv4^{-/-}}$ vs. WT, indicating that Trpv4 is necessary for development and maintenance of masticatory sensitization. We speculate that residual reduction of bite force in response to TMJ 
inflammation in $\operatorname{Trpv4^{-/}}$ mice is sustained by other mechanisms. However, in a focused screen for "pain-TRPs", we could not find an upregulation of any of the assessed genes in $\operatorname{Trpv4^{-/}}$ mice (see below). Compensatory gene expression in the trigeminal system in $\operatorname{Tr} p{ }^{-1-}{ }^{-}$mice awaits in-depth future studies with genome-wide scope.

Both components of masticatory sensitization, reduction of bite force and -rate, were less prominent in $\operatorname{Trpv}^{-/-}$mice (Fig. 3A, Suppl. Fig. 5), suggesting a role for TRPV4 channels in the nocifensive response to TMJ inflammation. Confirming and extending this concept, we observed that a single systemic application of TRPV4-specific inhibitor, HC-067047 (as characterized for systemic use in mice before [13]), led to a similar resistance to reduction of bite force and -rate as genetic deletion of $\operatorname{Trpv} 4$ (Fig. 3B, Suppl. Fig. 5). Interestingly, HC-067047, applied 24h past CFA-injection of the TMJs, lasted over several hours to restore bite force (as expected from its half-life). Furthermore, it did not have an effect on the residual attenuation of bite force of $\operatorname{Trpv4^{--}}$ mice, indicating absence of off-target effects and confirming the compound's specificity. Thus, both genetic deletion of Trpv4 as well as its temporary inhibition with a specific compound exert similar effects on pain behavior evoked by TMJ-inflammation. However, both methods do not specifically target the nervous system, a mandatory approach for future studies, given the present results. We did, on the other hand, examine carefully skeletal pathology by micro-CT and histopathology in $\operatorname{Trp} \mathrm{V}^{-/}$mice for comparison to WT (Fig. 1D-E, Suppl. Fig. 6). Surprisingly, skeletal changes of the mandibular condyle and joint histopathology were similar between genotypes ( $\operatorname{Trpv} 4^{+/+} v s . \operatorname{Trpv4^{-/-}}: 0.58 \pm 0.04$ vs. $0.66 \pm 0.07$ for bone fraction; $4 \pm 1.97$ vs. $4.83 \pm 1.44$ for total hyperplasia; $5.06 \pm 2.29$ vs. $6.41 \pm 1.46$ for synovitis), showing signs of bone loss and synovial inflammation in $\operatorname{Trpv4^{-/-}}$ mice to similar degree as in WT. This result indicates that TMJ-injection with CFA leads to joint inflammation and profound skeletal changes irrespective of Trpv4 genotype, a remarkable "negative" finding in view of documented TRPV4 expression in synoviocytes, chondrocytes, osteoblasts, macrophages and endothelial cells $[9 ; 10 ; 15 ; 19 ; 22 ; 35]$. Consequently, this result prompted us to focus on TRPV4's role in the TG.

\subsection{Regulatory mechanisms in the trigeminal ganglion in response to $\mathrm{TMJ}$ inflammation}

To better understand the relationship between bite force and Trpv4 we explored the trigeminal sensory innervation of the inflamed TMJ, and the dynamic TRPV4 expression in innervating TG neurons. After TMJ inflammation, TRPV4 was more abundant in TG homogenates, using Western blotting, peaking at $\mathrm{d} 3$ after induction of inflammation (2.25fold increase), a remarkable coincidence with the time-course of bite force reduction (Figs. 1B, 4A). This time-course was confirmed via TRPV4-specific immunolabeling, which showed that protein up-regulation was strictly neuronal (Fig. 4B). This regulation was confirmed and extended in a Trpv4 reporter mouse [40], showing increased reporter-gene expression following TMJ inflammation, suggesting increased Trpv 4 transcription as contributory (Fig. 4C). Immunostaining experiments demonstrated that the percentage of TRPV4-expressing TG neurons that innervate the TMJ approximately doubled in mice treated with CFA compared to control mice treated with IFA (2.95 vs. 5.5\%, p<0.05; Fig. 4D), indicating that TMJ inflammation up-regulates TRPV4 in these neurons, which we found were medium- or small-sized (Fig. 4E). However, with TMJ inflammation, TRPV4expressing sensory neurons that innervate the TMJ did not become more prevalent than in the TG overall (53.7\% of TMJ-innervating neurons vs. 50.9\% of all neurons). Moreover, TRPV4 up-regulation, from $34.3 \%$ to $50.9 \%$ (TRPV4+ of all TG neurons; $\mathrm{p}<0.001$ ), was not restricted to TMJ-innervating TG sensory neurons. This pattern suggests a possible crosssensitization between trigeminal branches. These findings suggest a delimited feed-forward mechanism whereby TRPV4-expression in TG sensory neurons is increased by TMJ inflammation in both TMJ-innervating neurons as well as others. These latter neurons might 
function in neurogenic inflammation (see Fig. 2A\&C, CGRP-expressing neurons), while providing sensory innervation to neighboring structures, which might become hypersensitive/allodynic.

Beyond upregulation of TRPV4 expression in TGs by TMJ inflammation, we asked whether expression of other pain-related Trp genes is regulated by TMJ inflammation or Trpv4 deletion, using qRT-PCR: Trpv1, Trpv2, Trpv3, Trpa1, Trpm2, Trpm3 and Trpm8 [6; 26; 33]. For WT, not $\operatorname{Trpv4^{--}}{ }^{-}$, there was a significant increase with inflammation for TRPV1 (1.88-fold increase) and TRPA1 (1.52-fold increase) (Fig. 5). For TRPM2 and TRPM3, there was significant down-regulation in $\operatorname{Trpv4^{-1}}$ vs. WT with inflammation (4.35- and 1.54-fold decrease for TRPM2 and TRPM3, respectively). Thus, the regulated expression of these "pain-TRPs" in the TG after TMJ inflammation was dependent on Trpv4. For TRPM3, this was also the case in non-inflamed controls. These findings indicate that TRPV4 regulates gene expression of other "pain-TRPs" in the TG after TMJ inflammation.

Overall, our findings imply that Trpv4 is critical for masticatory sensitization in TMJ inflammation, that a key locale is the TG where TMJ-innervating sensory neurons express TRPV4, which is upregulated by TMJ-inflammation, and that Trpv4 controls geneexpression of other "pain-TRPs" in the TG.

\subsection{Critical role of MEK-ERK MAP-kinase activation and its TRPV4-dependence in the trigeminal ganglion in response to TMJ inflammation}

Given the known role of extracellular-signal-regulated-kinase (ERK) signaling in nociceptive sensitization [20] and the documented role of MEK-ERK phosphorylation down-stream of TRPV4 in epithelial cells via $\mathrm{Ca}^{++}$influx and RAS-RAF signaling, and also in sensory neurons that innervate the gastrointestinal tract [25; 27], we asked whether ERK activation (phosphorylation, $4.21 \pm 0.18 \%$ of total TG neurons for control) was increased in TG neurons following TMJ inflammation. Phosphorylated-ERK (pERK) labeling was increased early and robustly $(8.93 \pm 0.37 \%, 7.92 \pm 0.59 \%$ and $7.38 \pm 0.92 \%$ at $3 \mathrm{~h}, 1 \mathrm{~d}$ and $3 \mathrm{~d}$ CFA, respectively) after injection of CFA, and expressed in TG sensory neurons (Fig. 6A). TRPV4 was co-expressed in pERK-expressing TG neurons that innervate the TMJ (Fig. 6B), for example co-expression increased significantly after TMJ-inflammation (on d3, 9\% for IFA-injection, $21 \%$ for CFA-injection). This finding suggests pERK-mediated reprogramming of TG sensory neurons in TMJ inflammation that involves TRPV4-signaling [4]. To test this concept in-vivo, we subjected dn-MEK-transgenic mice, which are incapacitated to phosphorylate ERK exclusively in their neurons, to TMJ inflammation [41]. Remarkably, their bite force reduction over time resembled that of $\operatorname{Trpv4^{-1}}$ mice (Fig. 6C). Since the dnMEK-transgene is driven by an exclusively neuronal promoter, and since we verified transgene expression in the mouse TG (Fig. 6C), our findings suggest that a critical signaling mechanism for nocifensive behavior is operative in TG sensory neurons, not further up-stream in the pain pathway, not in astrocytes (where Trpv4 is also expressed [5]) or activated microglia in pain transmission. Importantly, the TG is a critical locale, rather than its peripheral targets because the dnMEK-transgene is only expressed in neurons, meaning both peripheral sensory neurons and within the CNS. We therefore focused on the TG and examined pERK-expression over time after TMJ-inflammation in WT, Trpv $4^{-1-}$ and dnMEK-transgenic mice. We found more than doubling of pERK expression in WT $3 \mathrm{~h}$ after CFA injection, which remained elevated until d3. In contrast, both $\operatorname{Trpv4^{-1}}$ and dnMEKtransgenic mice failed to up-regulate pERK, suggesting that TRPV4 functions upstream of ERK phosphorylation in TG sensory neurons. No significant differences in basal levels of pERK in TG sensory neurons were detected between WT, $\operatorname{Trpv4^{--}}$ and dn-MEK-transgenic mice (data not shown) 


\section{Discussion}

We established a key role for TRPV4 ion channels in the pain response to TMJ inflammation as a model for pain of human TMJD. Our findings imply TRPV4 expression in the TG as a critical locale for behavioral sensitization, which we assessed by adapting bite force methodology to the laboratory mouse, and subjecting $\operatorname{Trpv4^{-1}}$ mice to TMJ inflammation. Human TMJD, on the other hand, is not caused by irritant-arthritis. Bearing in mind this caveat we used externally-induced TMJ inflammation in mice as a mechanistic invivo model to study pain behavior and its neural and inflammatory underpinnings.

Our main findings, showing that TRPV4-expression in the TG plays a critical role in the nocifensive response, include: Firstly, histopathological evidence of TMJ joint inflammation and micro-CT evidence of bone loss in the mandibular condyle were obtained irrespective of Trpv4 genotype, despite documented presence of functional TRPV4 expression in synoviocytes, chondrocytes, osteoblasts, striated muscle and macrophages $[9 ; 10 ; 15 ; 19 ; 22$; 35]. We are confident that our metrics faithfully reflect inflammatory activity involving the TMJ, between injection of CFA and assessments on d13. Bone loss in an inflamed joint has been reported previously [24], is an indicator of TMJ arthritis rather than masticatory muscle myositis, and accurately reflects arthritic changes induced in the TMJ. When considering the critical locale for the different pain behavior between WT and $\operatorname{Trpv4^{-/}}{ }^{-}$, we focused in particular on the TG in view of the apparent - and surprising - lack of differences between genotypes for musculoskeletal pathology. We corroborated TRPV4-expression in TGs, consistent with earlier findings, plus demonstrated TRPV4 in TMJ-innervating TG neurons. In addition, TRPV4 expressing TMJ-innervating TG neurons were predominantly small- and medium-sized, and an appreciable proportion of these neurons showed colocalization with peptidergic and non-peptidergic markers, suggesting that they might function as nociceptors. Finally, TRPV4 expression in the TG increased in synchrony with clinical severity after TMJ inflammation. Based on loss-of-function experiments of Trpv4, our findings clarify the role of this gene, and are an extension of a recent study suggesting a link of TRPV4 to arthritis, using TMJ irritation and inflammation as an exemplar [10]. Local chemical activation of TRPV4 was employed, with focus on the TMJ and proteolytic mechanisms of inflammation [10].

Secondly, dn-MEK-transgenic mice, animals that have reduced capability to phosphorylate ERK, revealed a similar bite force phenotype as $\operatorname{Trpv4^{-1}}$ mice, together with up-regulation of pERK in TG neurons in response to TMJ inflammation, in detail increased percentage of pERK+/TRPV4+ in TG sensory neurons that innervate the TMJ. Another important issue is that the dn-MEK-transgene is not expressed outside the nervous system, and that the percentage of TRPV4/pERK-colocalization in the TG increased significantly with TMJ inflammation.

Overall, these two arguments support our concept that the TG is a key locale for TMJ inflammation in terms of TRPV4 expression. However, co-contribution of additional CNSmechanisms cannot be discounted, such as modulation of pain transmission by TRPV4expressing astrocytes, as well as TRPV4-independent mechanisms that depend on ERK phosphorylation.

In terms of using bite force in mice to quantify nocifensive behavior in response to TMJ inflammation, other innovative methods have been reported recently that also have considerable alignment with clinical features of TMJD [11]. These methods complement and advance the well-established, yet exclusively experimental head aversion test with vonFrey hairs, which relies on facial skin mechanical allodynia in response to TMJ inflammation [38]. Facial mechanical allodynia, however, is not a dominant clinical feature 
of TMJD. Taken together, the direct measure of bite force provides a novel quantitative approach of quantifying TMJ pain in the mouse model.

Finally, our conclusions suggest that TRPV4 is a reasonable and bona-fide drug target for treatment of TMJD based also on effective use of the TRPV4-specific inhibitor, HC-067047, and the high degree of conservation between human and mouse TRPV4.

\section{Supplementary Material}

Refer to Web version on PubMed Central for supplementary material.

\section{Acknowledgments}

This study was supported by NIH grants DE018549 (WL), DE19440 (FW), NS48602 (RG) and AR048182 (FG), support from the Duke Institute for Brain Science (DIBS) to WL and FW, a Leon Goldberg Fellowship (Nicholas School for the Environment, Duke University) to YC, a Minority Supplement DE018549-S to CM, and fellowship support to JHH from Keimyung University School of Medicine, Daegu, South Korea. We thank Drs. Sidney Simon, Timothy Collins and Ru-rong Ji (all Duke University) for careful reading of the manuscript.

\section{References}

1. Alessandri-Haber N, Dina OA, Joseph EK, Reichling DB, Levine JD. Interaction of transient receptor potential vanilloid 4 , integrin, and Src tyrosine kinase in mechanical hyperalgesia. $\mathrm{J}$ Neurosci. 2008; 28:1046-57. [PubMed: 18234883]

2. Arcan M, Zandman F. A method for in vivo quantitative occlusal strain and stress analysis. J Biomech. 1984; 17:67-79. [PubMed: 6725296]

3. Auerbach SM, Laskin DM, Frantsve LM, Orr T. Depression, pain, exposure to stressful life events, and long-term outcomes in temporomandibular disorder patients. J Oral Maxillofac Surg. 2001; 59:628-33. [PubMed: 11381383]

4. Basbaum, AI.; Braz, JM. Transgenic Mouse Models for the Tracing of "Pain” Pathways. In: Kruger, L.; Light, AR., editors. Translational Pain Research: From Mouse to Man. Boca Raton, FL: 2010.

5. Benfenati V, Amiry-Moghaddam M, Caprini M, Mylonakou MN, Rapisarda C, Ottersen OP, Ferroni S. Expression and functional characterization of transient receptor potential vanilloidrelated channel 4 (TRPV4) in rat cortical astrocytes. Neuroscience. 2007; 148:876-92. [PubMed: 17719182]

6. Bevan S, Andersson DA. TRP channel antagonists for pain--opportunities beyond TRPV1. Curr Opin Investig Drugs. 2009; 10:655-63.

7. Brierley SM, Page AJ, Hughes PA, Adam B, Liebregts T, Cooper NJ, Holtmann G, Liedtke W, Blackshaw LA. Selective role for TRPV4 ion channels in visceral sensory pathways. Gastroenterology. 2008; 134:2059-69. [PubMed: 18343379]

8. Choy E, Kydd WL. Bite force duration: a diagnostic procedure for mandibular dysfunction. J Prosthet Dent. 1988; 60:365-8. [PubMed: 3172020]

9. Clark AL, Votta BJ, Kumar S, Liedtke W, Guilak F. Chondroprotective role of the osmotically sensitive ion channel transient receptor potential vanilloid 4: age- and sex-dependent progression of osteoarthritis in Trpv4-deficient mice. Arthritis Rheum. 2010; 62:2973-83. [PubMed: 20583100]

10. Denadai-Souza A, Martin L, de Paula MA, de Avellar MC, Muscara MN, Vergnolle N, Cenac N. Role of transient receptor potential vanilloid 4 in rat joint inflammation. Arthritis Rheum. 2012; 64:1848-58. [PubMed: 22184014]

11. Dolan JC, Lam DK, Achdjian SH, Schmidt BL. The dolognawmeter: a novel instrument and assay to quantify nociception in rodent models of orofacial pain. J Neurosci Methods. 2010; 187:207-15. [PubMed: 20096303]

12. Dubner R, Sessle BJ, Storey AT. Temporomandibular joint. Periodontium and temporomandibular joint. The neural bases of oral and facial function. 1978; 6:160-74.

13. Everaerts W, Zhen X, Ghosh D, Vriens J, Gevaert T, Gilbert JP, Hayward NJ, McNamara CR, Xue F, Moran MM, Strassmaier T, Uykal E, Owsianik G, Vennekens R, De Ridder D, Nilius B, Fanger 
CM, Voets T. Inhibition of the cation channel TRPV4 improves bladder function in mice and rats with cyclophosphamide-induced cystitis. Proc Natl Acad Sci USA. 2010; 107:19084-9. [PubMed: 20956320]

14. Griffin TM, Fermor B, Huebner JL, Kraus VB, Rodriguiz RM, Wetsel WC, Cao L, Setton LA, Guilak F. Diet-induced obesity differentially regulates behavioral, biomechanical, and molecular risk factors for osteoarthritis in mice. Arthritis Res Ther. 2010; 12:R130. [PubMed: 20604941]

15. Guilak F, Leddy HA, Liedtke W. Transient receptor potential vanilloid 4: The sixth sense of the musculoskeletal system? Ann N Y Acad Sci. 2010; 1192:404-9. [PubMed: 20392266]

16. Guo W, Wang H, Zou S, Wei F, Dubner R, Ren K. Long lasting pain hypersensitivity following ligation of the tendon of the masseter muscle in rats: a model of myogenic orofacial pain. Mol Pain. 2010; 6:40. [PubMed: 20633279]

17. Gynther GW, Dijkgraaf LC, Reinholt FP, Holmlund AB, Liem RS, de Bont LG. Synovial inflammation in arthroscopically obtained biopsy specimens from the temporomandibular joint: a review of the literature and a proposed histologic grading system. J Oral Maxillofac Surg. 1998; 56:1281-6. [PubMed: 9820216]

18. Harper RP, Kerins CA, Talwar R, Spears R, Hutchins B, Carlson DS, McIntosh JE, Bellinger LL. Meal pattern analysis in response to temporomandibular joint inflammation in the rat. J Dent Res. 2000; 79:1704-11. [PubMed: 11023267]

19. Itoh Y, Hatano N, Hayashi H, Onozaki K, Miyazawa K, Muraki K. An environmental sensor, TRPV4 is a novel regulator of intracellular Ca2+ in human synoviocytes. Am J Physiol Cell Physiol. 2009; 297:C1082-90. [PubMed: 19759329]

20. Ji RR, Gereau RW, Malcangio M, Strichartz GR. MAP kinase and pain. Brain Res Rev. 2009; 60:135-48. [PubMed: 19150373]

21. Kawamura Y. Neurogenesis of mastication. Front Oral Physiol. 1974; 1:77-120. [PubMed: 4279203]

22. Kochukov MY, McNearney TA, Yin H, Zhang L, Ma F, Ponomareva L, Abshire S, Westlund KN. Tumor necrosis factor-alpha (TNF-alpha) enhances functional thermal and chemical responses of TRP cation channels in human synoviocytes. Mol Pain. 2009; 5:49. [PubMed: 19695100]

23. Kogawa EM, Calderon PS, Lauris JR, Araujo CR, Conti PC. Evaluation of maximal bite force in temporomandibular disorders patients. J Oral Rehabil. 2006; 33:559-65. [PubMed: 16856953]

24. Kuroki Y, Honda K, Kijima N, Wada T, Arai Y, Matsumoto N, Iwata K, Shirakawa T. In vivo morphometric analysis of inflammatory condylar changes in rat temporomandibular joint. Oral Dis. 2011; 17:499-507. [PubMed: 21496185]

25. Lechner SG, Markworth S, Poole K, Smith ES, Lapatsina L, Frahm S, May M, Pischke S, Suzuki M, Ibanez-Tallon I, Luft FC, Jordan J, Lewin GR. The molecular and cellular identity of peripheral osmoreceptors. Neuron. 2011; 69:332-44. [PubMed: 21262470]

26. Levine JD, Alessandri-Haber N. TRP channels: targets for the relief of pain. Biochim Biophys Acta. 2007; 1772:989-1003. [PubMed: 17321113]

27. Li J, Kanju P, Patterson M, Chew WL, Cho SH, Gilmour I, Oliver T, Yasuda R, Ghio A, Simon SA, Liedtke W. TRPV4-mediated calcium influx into human bronchial epithelia upon exposure to diesel exhaust particles. Environ Health Perspect. 2011; 119:784-93. [PubMed: 21245013]

28. Liedtke W, Choe Y, Marti-Renom MA, Bell AM, Denis CS, Sali A, Hudspeth AJ, Friedman JM, Heller S. Vanilloid receptor-related osmotically activated channel (VR-OAC), a candidate vertebrate osmoreceptor. Cell. 2000; 103:525-35. [PubMed: 11081638]

29. Liedtke W, Friedman JM. Abnormal osmotic regulation in trpv4-/- mice. Proc Natl Acad Sci USA. 2003; 100:13698-703. [PubMed: 14581612]

30. Lund JP. Mastication and its control by the brain stem. Crit Rev Oral Biol Med. 1991; 2:33-64. [PubMed: 1912143]

31. Maixner W, Fillingim R, Booker D, Sigurdsson A. Sensitivity of patients with painful temporomandibular disorders to experimentally evoked pain. Pain. 1995; 63:341-51. [PubMed: 8719535]

32. Mutai H, Heller S. Vertebrate and invertebrate TRPV-like mechanoreceptors. Cell Calcium. 2003; 33:471-8. [PubMed: 12765692] 
33. Numazaki M, Tominaga M. Nociception and TRP Channels. Curr Drug Targets CNS Neurol Disord. 2004; 3:479-85. [PubMed: 15578965]

34. Owatz CB, Khan AA, Schindler WG, Schwartz SA, Keiser K, Hargreaves KM. The incidence of mechanical allodynia in patients with irreversible pulpitis. J Endod. 2007; 33:552-6. [PubMed: 17437870]

35. Phan MN, Leddy HA, Votta BJ, Kumar S, Levy DS, Lipshutz DB, Lee SH, Liedtke W, Guilak F. Functional characterization of TRPV4 as an osmotically sensitive ion channel in porcine articular chondrocytes. Arthritis Rheum. 2009; 60:3028-37. [PubMed: 19790068]

36. Purcell P, Joo BW, Hu JK, Tran PV, Calicchio ML, O’Connell DJ, Maas RL, Tabin CJ. Temporomandibular joint formation requires two distinct hedgehog-dependent steps. Proc Natl Acad Sci USA. 2009; 106:18297-302. [PubMed: 19815519]

37. Reisine ST, Fertig J, Weber J, Leder S. Impact of dental conditions on patients' quality of life. Community Dent Oral Epidemiol. 1989; 17:7-10. [PubMed: 2645088]

38. Ren K. An improved method for assessing mechanical allodynia in the rat. Physiol Behav. 1999; 67:711-6. [PubMed: 10604842]

39. Ross CF, Dharia R, Herring SW, Hylander WL, Liu ZJ, Rafferty KL, Ravosa MJ, Williams SH. Modulation of mandibular loading and bite force in mammals during mastication. J Exp Biol. 2007; 210:1046-63. [PubMed: 17337717]

40. Ryskamp DA, Witkovsky P, Barabas P, Huang W, Koehler C, Akimov NP, Lee SH, Chauhan S, Xing W, Renteria RC, Liedtke W, Krizaj D. The polymodal ion channel transient receptor potential vanilloid 4 modulates calcium flux, spiking rate, and apoptosis of mouse retinal ganglion cells. J Neurosci. 2011; 31:7089-101. [PubMed: 21562271]

41. Shalin SC, Zirrgiebel U, Honsa KJ, Julien JP, Miller FD, Kaplan DR, Sweatt JD. Neuronal MEK is important for normal fear conditioning in mice. J Neurosci Res. 2004; 75:760-70. [PubMed: 14994337]

42. Strotmann R, Harteneck C, Nunnenmacher K, Schultz G, Plant TD. OTRPC4, a nonselective cation channel that confers sensitivity to extracellular osmolarity. Nat Cell Biol. 2000; 2:695-702. [PubMed: 11025659]

43. Svensson P, Arendt-Nielsen L, Bjerring P, Bak P, Hjorth T, Troest T. Human mastication modulated by experimental trigeminal and extra-trigeminal painful stimuli. J Oral Rehabil. 1996; 23:838-48. [PubMed: 8971646]

44. Swift JQ, Roszkowski MT, Alton T, Hargreaves KM. Effect of intra-articular versus systemic antiinflammatory drugs in a rabbit model of temporomandibular joint inflammation. J Oral Maxillofac Surg. 1998; 56:1288-95. [PubMed: 9820217]

45. Turman JE Jr. The development of mastication in rodents: from neurons to behaviors. Arch Oral Biol. 2007; 52:313-6. [PubMed: 17055446]

46. Wei X, Edelmayer RM, Yan J, Dussor G. Activation of TRPV4 on dural afferents produces headache-related behavior in a preclinical rat model. Cephalalgia. 2011; 31:1595-1600. [PubMed: 22049072]

47. Williams SH, Peiffer E, Ford S. Gape and bite force in the rodents Onychomys leucogaster and Peromyscus maniculatus: does jaw-muscle anatomy predict performance? J Morphol. 2009; 270:1338-47. [PubMed: 19480012]

48. Yamada Y, Yamamura K, Inoue M. Coordination of cranial motoneurons during mastication. Respir Physiol Neurobiol. 2005; 147:177-89. [PubMed: 16087147]

49. Zhang Y, Wang YH, Ge HY, Arendt-Nielsen L, Wang R, Yue SW. A transient receptor potential vanilloid 4 contributes to mechanical allodynia following chronic compression of dorsal root ganglion in rats. Neurosci Lett. 2008; 432:222-7. [PubMed: 18206306] 
Trpv4 is critical for sensitization of trigeminal ganglion sensory neurons that innervate the inflamed temporomandibular joint, using bite force measurements in the laboratory mouse to measure nocifensive behavior. 

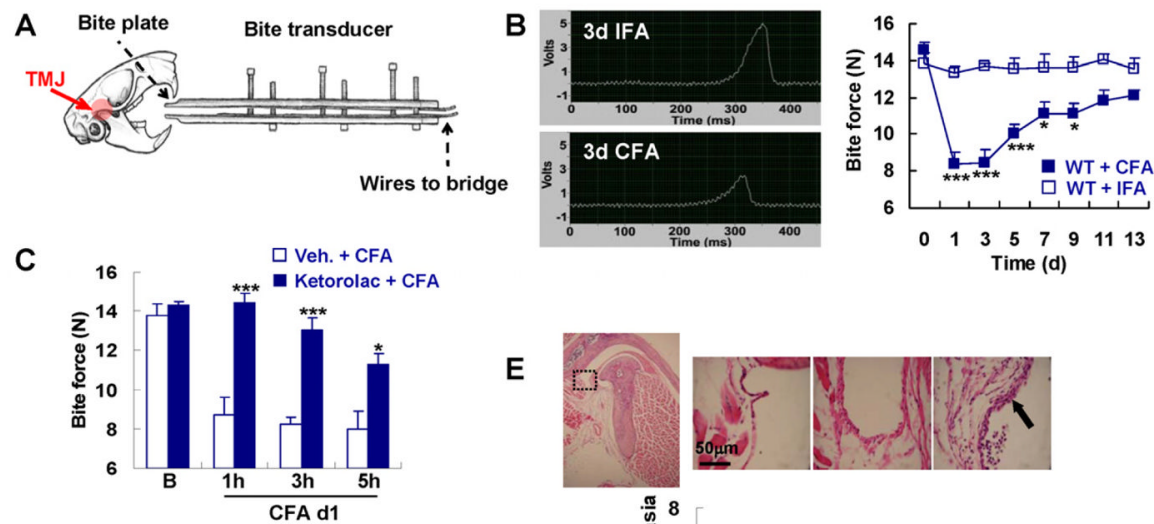

E
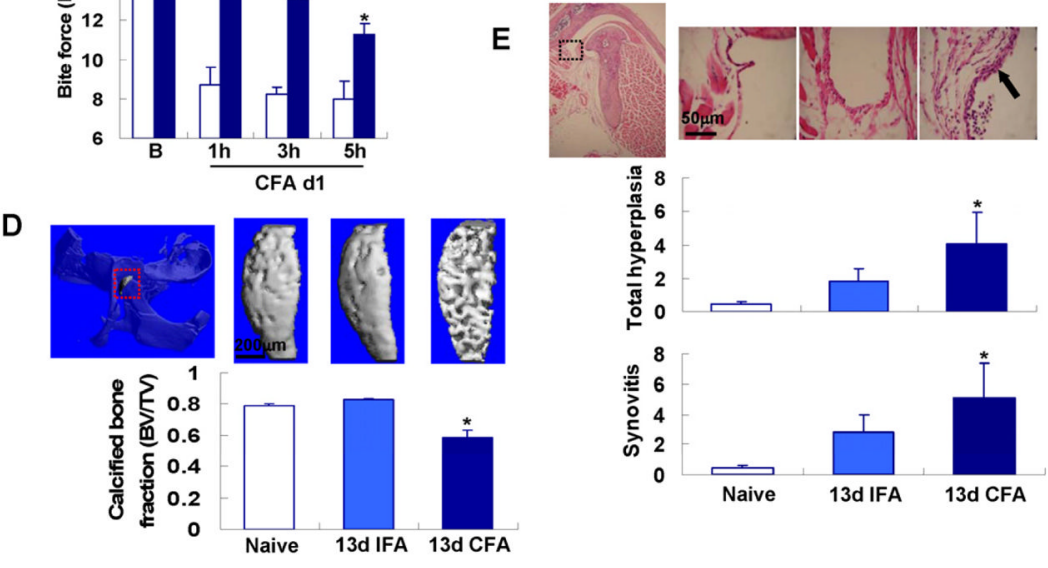

Fig. 1.

Bite force assessment and TMJ inflammation in mice. (A) shows schematically the bite force transducer and TMJ targeting by micro-injections. (B) shows reduced amplitude of the voltage output during biting in response to CFA. Note significant attenuation of bite force over 9 days in response to CFA (CFA group $\mathrm{n}=13$, IFA group $\mathrm{n}=8$; *** $\mathrm{p}<0.001$, * $\mathrm{p}<0.05$; one-way ANOVA with Tukey post test). (C) shows reversal of bite force attenuation by Ketorolac, with complete elimination at the $1 \mathrm{~h}$ time-point ( $=25 \mathrm{~h}$ after $\mathrm{CFA}$ injection), and thereafter diminishing (group size $\mathrm{n}=6$; $* * * \mathrm{p}<0.001, * \mathrm{p}<0.05$ vs. vehicle; two-tail $t$ test). Ketorolac did not alter the baseline bite force (data not shown). (D) Representative microCT images of the head of the mandibular condyle (highlighted in red dotted box). This region of the condyle was utilized to measure bone parameters, in particular calcified bone fraction ( $\mathrm{n}=3$ for naïve and $\mathrm{n}=4-5$ for CFA or IFA groups, ${ }^{*} \mathrm{p}<0.05$ compared to naïve and IFA; non-parametric Kruskall-Wallis test). (E) Representative H\&E-stained sections of the TMJ synovial membrane. Lower-magnification micrograph (left-hand), illustrates the area of higher magnification by a black box (dotted). For explanation of total hyperplasia and synovitis scores, see Methods section. Note cellular infiltrate and synovial thickening (arrow) in CFA-injected animal on $\mathrm{d} 13$ ( $\mathrm{n}=3$ for naïve and $\mathrm{n}=4-5$ for CFA or IFA groups, ${ }^{*} \mathrm{p}<0.05$ CFA vs. IFA on d13; non-parametric Kruskall-Wallis test). 

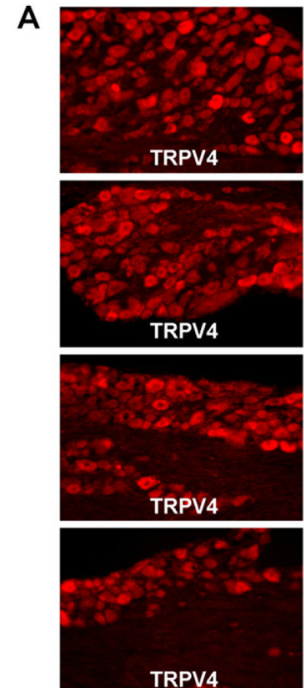

TRPV4

B

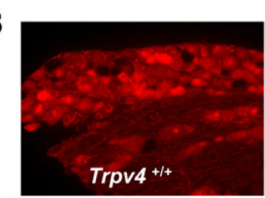

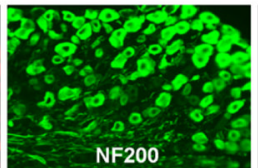

NF200
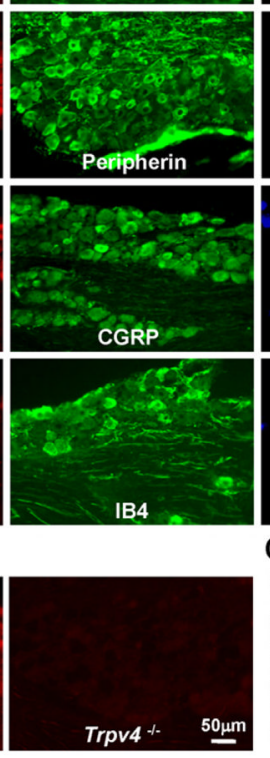

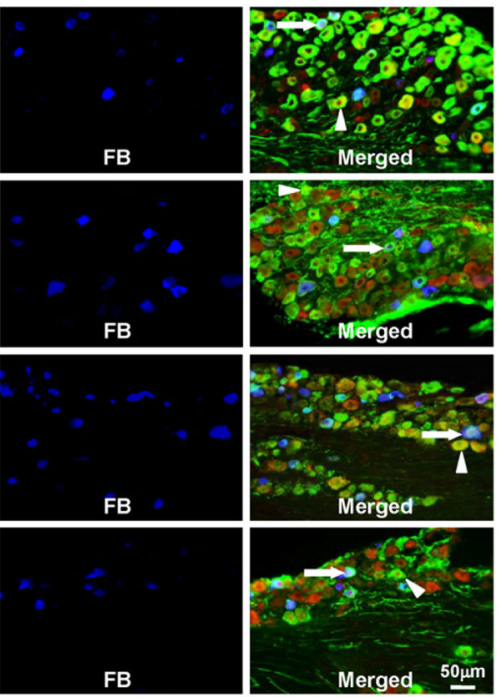

C $80 \square$ of all TRPV4+ $\quad$ of TRPV4+/FB+

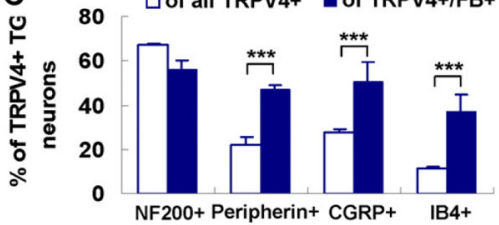

Fig. 2.

TRPV4 is expressed in TG sensory neurons that innervate the TMJ. (A) shows colocalization of TG neurons' TRPV4 expression with FB tracing that is originating from the TMJ (blue); note co-labeling with NF200, peripherin, CGRP and IB4 markers (arrow heads: TRPV4+marker; arrows: TRPV4+FB+marker). (B) illustrates specificity of the TRPV4-specific antibody using TG sections from Trpv $4^{-1-}$ mice. (C) \% of TRPV4+ neurons that co-express phenotypic markers from (A) for all neurons (white bars) and for TMJ-innervating $(=\mathrm{FB}+$ ) neurons (blue bars). For all neurons, $\mathrm{n}=5$ animals, $>250$ neurons per animal were assessed, for TMJ-innervating neurons, $\mathrm{n}=4$ animals, $>50$ neurons per animal (*** $\mathrm{p}<0.001$; two-tail $t$ test). 

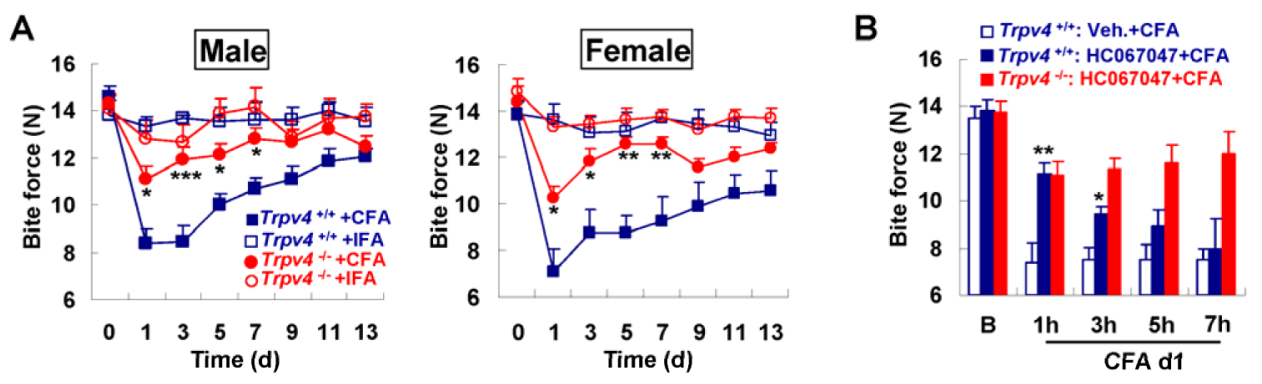

Fig. 3.

Attenuation of bite force in response to TMJ inflammation depends on Trpv4. (A) illustrates dependence of bite force-attenuation on Trpv4 with similar effect in both sexes, in response to CFA vs. IFA over 2 weeks. Note absence of a measurable reduction when injecting IFA as control. IFA groups $n=8$, CFA groups $n=13$ for males, $n=6-8$ for females $(* * * p<0.001$, $* * \mathrm{p}<0.01, * \mathrm{p}<0.05$; one-way ANOVA with Tukey post test). (B) shows effects of systemic application of TRPV4-specific inhibitor, HC-067047, applied 24h after TMJ injection with CFA. Note reduction of the attenuation of bite force to the almost exact same level as in $\operatorname{Trpv} 4^{-1-}$ mice $1 \mathrm{~h}$ after application of compound. At $3 \mathrm{~h}$ the compound loses its effect, at $5 \mathrm{~h}$ and $7 \mathrm{~h}$ no longer different from vehicle-injected. Also note the HC-067047 has no effect in Trpv $4^{-1-}$ mice, indicating lack of off-target effects in our TMJ inflammation paradigm (group $\mathrm{n}=6$; ** $\mathrm{p}<0.01,{ }^{*} \mathrm{p}<0.05$ vs. vehicle-treated; two-tail $t$ test). HC-067047 did not alter the baseline bite force (data not shown). 

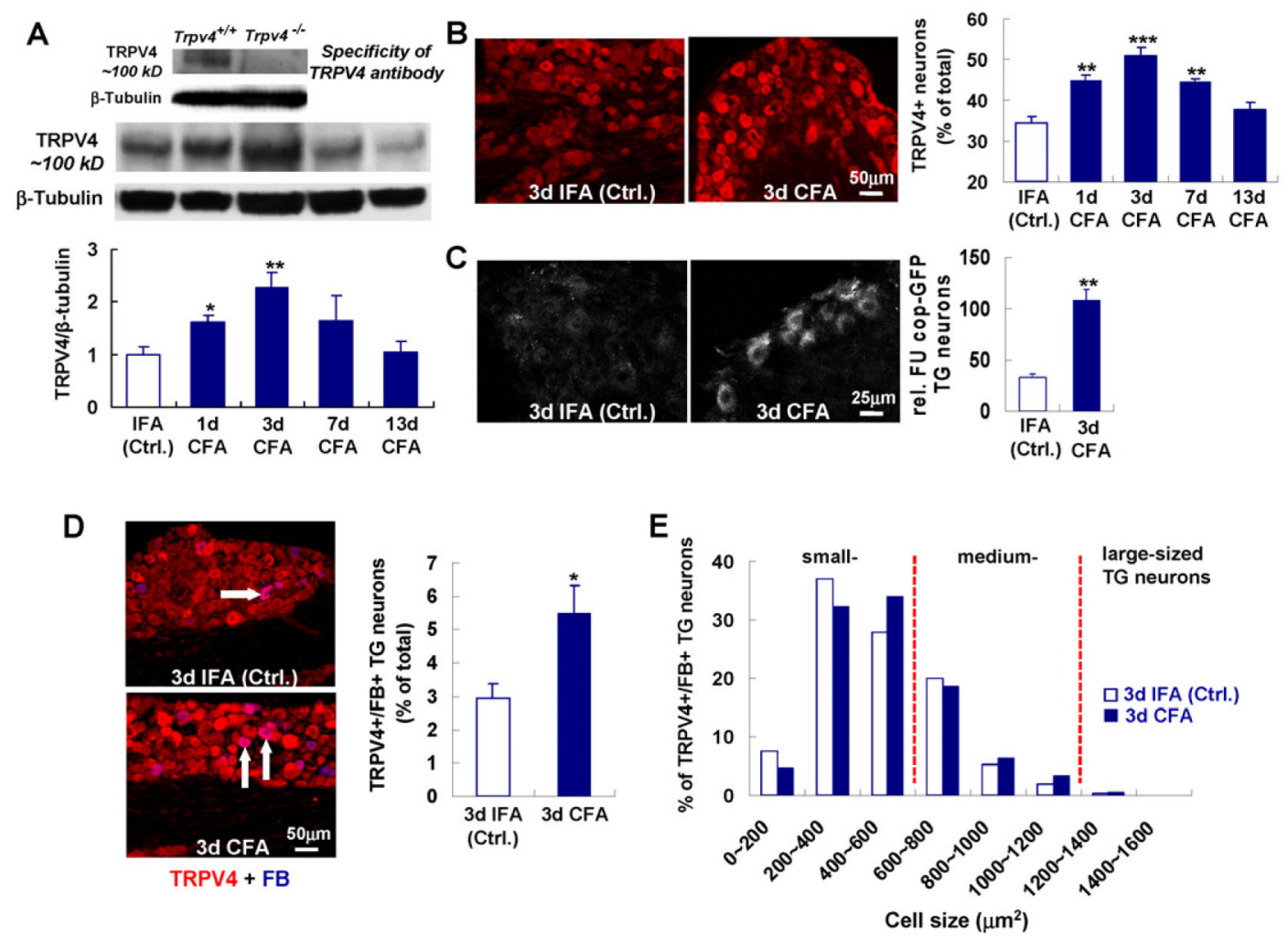

Fig. 4.

Increased TRPV4 expression in TG neurons in response to TMJ inflammation. (A) shows increased TG protein expression using Western-blot with specific antibody. (B) shows that this is restricted predominantly to neurons. Note that time-course parallels clinical course for both protein expression studies. $\mathrm{n}=5$ mice per time-point for Western, $\mathrm{n}=4-5$ per time-point immunolabeling $(* * * \mathrm{p}<0.001$, ** $\mathrm{p}<0.01, * \mathrm{p}<0.05$; two-tail $t$ test). (C) Increased expression of Trpv4 in TG neurons as revealed by a transgenic Trpv4 reporter mouse [40]. Exemplary fluorescent micrographs from a CFA vs. an IFA injected mouse are shown in the left-hand panels. Next, note bar diagram depicting significant increase in average GFPfluorescence for CFA vs. IFA-injected mice, $\mathrm{n}=4$ per group (** $\mathrm{p}<0.01$; two-tail $t$ test). (D) shows colocalization of TRPV4 and FB (arrows indicating neurons TRPV4+/FB+), indicating TMJ-innervation, and its significant increase with CFA ( $\mathrm{n}=6$ per group; ${ }^{*} \mathrm{p}<0.05$; two-tail $t$ test). (E) shows size distribution of TRPV4-expressing and TMJ-innervating TG neurons in the small- $\left(0-600 \mu \mathrm{m}^{2}\right)$ and medium-sized $\left(600-1200 \mu \mathrm{m}^{2}\right)$ cohort ( $\mathrm{n}=6$ animals/ group), note strong reduction of their number in large-sized neurons. 


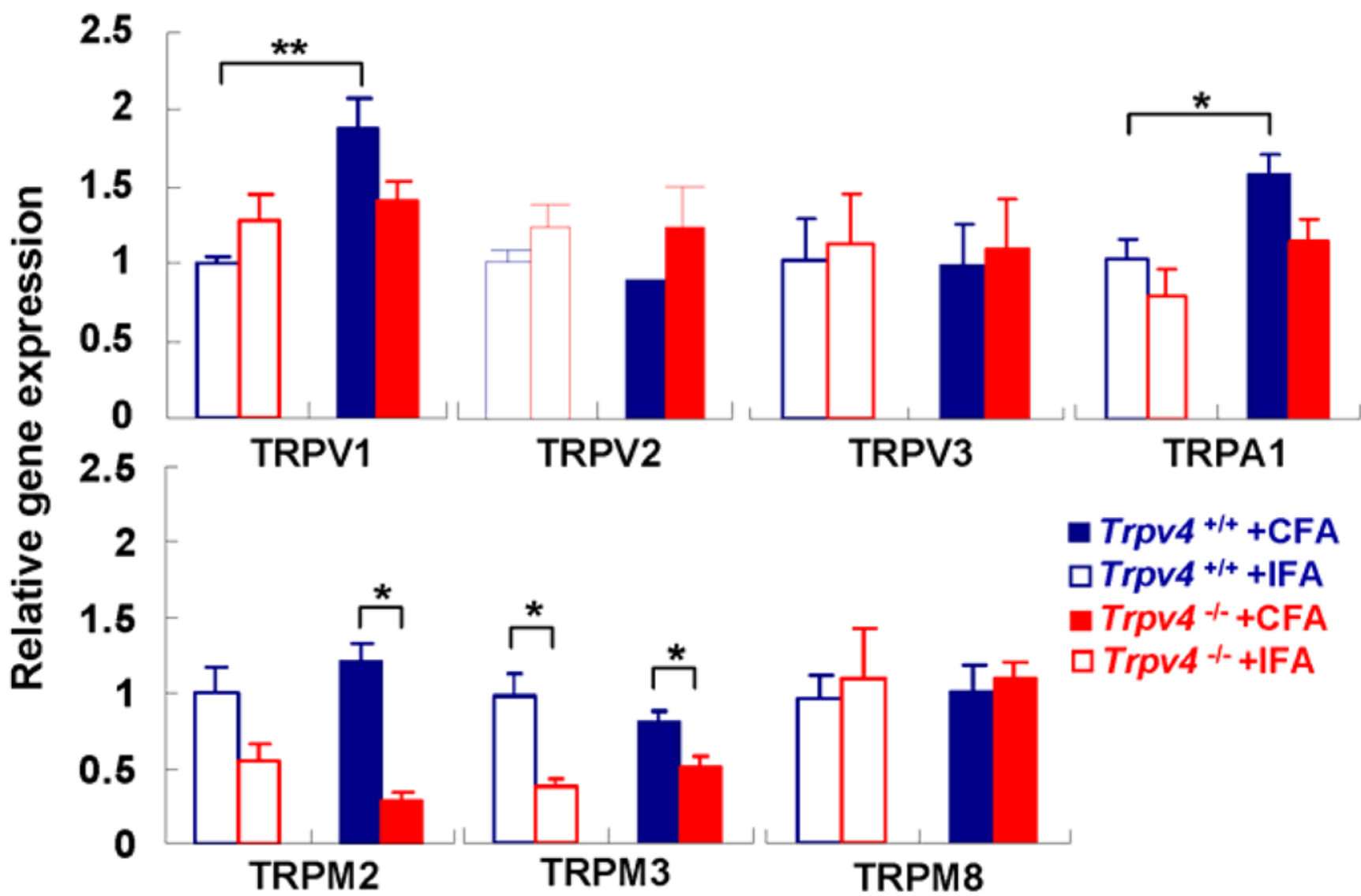

Fig. 5.

Dependence of regulation of "pain TRPs" in the TG on Trpv4. Bar diagram shows Trpv4 dependence for upregulation of Trpv1 and Trpal transcripts with TMJ inflammation in WT mice, also $\operatorname{Trpv} 4$ dependence for expression of $\operatorname{Trpm} 2$ and $\operatorname{Trpm} 3$ with inflammation, for Trpm3 also without inflammation ( $\mathrm{n}=5$ mice per group, $3 \mathrm{~d}$ time-point, ${ }^{*} \mathrm{p}<0.05,{ }^{*} \mathrm{p}<0.01$; two-tail $t$ test). $\beta$-tubulin ${ }_{\text {III }}$ was used as housekeeping gene. 

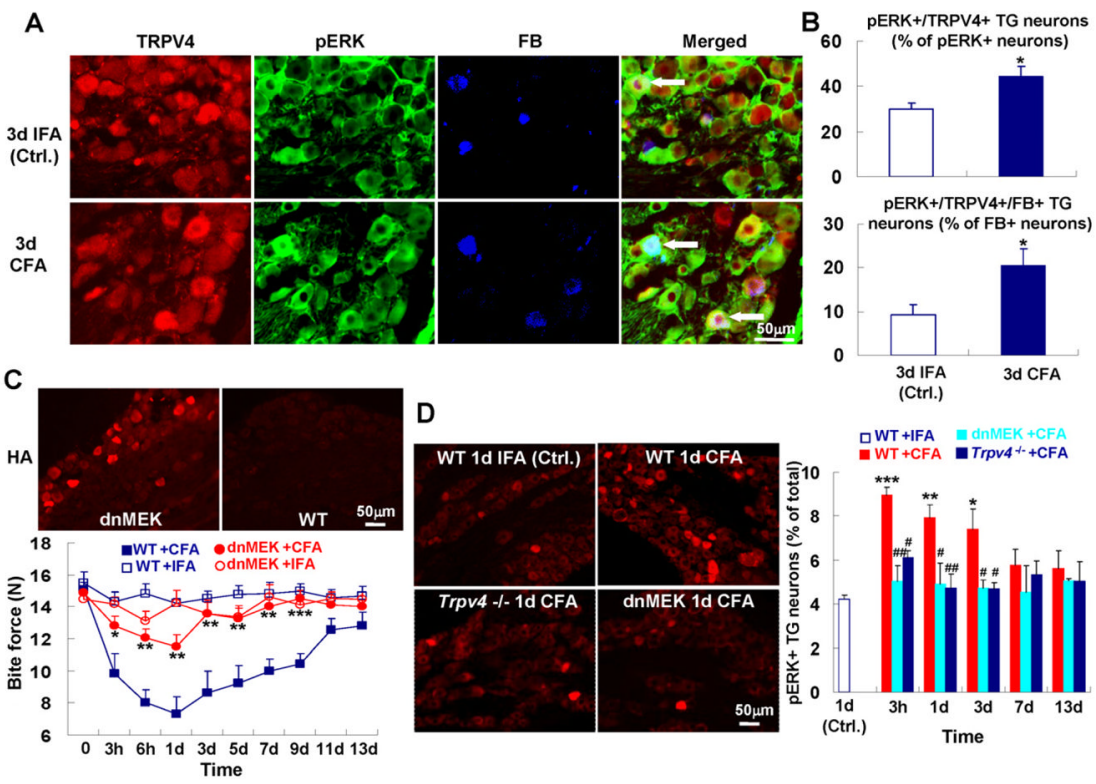

Fig. 6.

MAP-kinase signaling down-stream of TRPV4 is critical for reduction of bite force in TMJ inflammation. (A) pERK-TRPV4 co-expressing TG neurons innervate the TMJ. (B) pERK expressing TG neurons that innervate the TMJ and co-express TRPV4. The upper panel depicts the increase for pERK-TRPV4 co-expressing neurons, of all pERK+ TG neurons, the lower panel the increase for TMJ-innervating pERK-TRPV4 co-expressing neurons, of all TMJ-innervating neurons ( $\mathrm{n}=5$ animals per group; *p<0.05; two-tail $t$ test). (C) ERK phosphorylation in neurons is required for reduction of bite force in response to TMJ inflammation. Micrographs: note presence of the transgene, identified by HAimmunolabeling in the TG of a dnMEK-transgenic mouse. Lower panel: Note reversal of attenuation of bite force for dn-MEK-transgenic mice to levels as seen in $\operatorname{Trpv4^{-1-}}$ mice $\left(\mathrm{n}=7-9\right.$ mice per group; ${ }^{*} \mathrm{p}<0.05, * * \mathrm{p}<0.01, * * * \mathrm{p}<0.001$; one-way ANOVA with Tukey post test). (D) Increase of pERK expressing TG neurons in response to TMJ inflammation depends on Trpv4. Left-hand micrographs show pERK expression in the TG, revealed by immunolabeling. Right-hand bar graphs depict quantitation. Note early and robust increase of pERK-expression in the TG, and virtually complete lack thereof in $\operatorname{Trpv4^{--}}$ mice; also note similar lack in dn-MEK-transgenic mice, as expected $(n=4-5$ mice per group; $* \mathrm{p}<0.05$, **p $<0.01, * * * \mathrm{p}<0.001$, WT+CFA vs. WT+IFA; \#p $<0.05$, \#\#p $<0.01$ Trp $4^{-l-}$ or dn-MEKtransgenic mice vs. WT, all + CFA; two-tail $t$ test). 